Allpanchis, año XLVIII, núm. 87. Arequipa, enero-junio de 2021, pp. 323-335.

ISSN impreso 0252-8835 / ISSN en línea 2708-8960

DOI: https://doi.org/10.36901/allpanchis.v48i87.1212

\title{
Escritura en quechua: las ciudades letradas de Alan Durston
}

\author{
Carlos Arrizabalaga \\ Universidad de Piura (Piura, Perú) \\ Correo electrónico: carlos.arrizabalaga@udep.edu.pe
}

Código ORCID: 0000-0003-3097-057X

Alan Durston, profesor asociado de la York University de Toronto (Canadá), publicó recientemente en Allpanchis un acertado diagnóstico del importante protagonismo alcanzado por la historiografía relativa a las lenguas indígenas de América Latina (Durston, 2020). Allí formulaba varias interrogantes:

¿Qué se puede aprender sobre — y de— el vaivén demográfico y social de las lenguas indígenas a través del tiempo? ¿Cómo era el manejo de la comunicación entre idiomas diferentes en las sociedades colonial y nacional? ¿Cuáles fueron los efectos culturales y sociales de la diversidad lingüística y del multilingüismo? ¿Quiénes hablaban lenguas indígenas, en qué contextos y por qué? Lo que Peter Burke (1993) denomina la «historia social de la lengua» —una sociolingüística histórica— ha recibido poca atención en América Latina. ${ }^{1}$

1 Durston (2020, pp. 439-440). Durston (2015) había publicado el mismo trabajo, en una versión anterior, en lengua inglesa. 
En efecto, la historia social de las lenguas tiene muchos capítulos que merecen la atención de los especialistas y uno de los que revelan lecciones de importante calado es la investigación realizada por Alan Durston sobre los contextos y las funciones de la escritura, en este caso de la escritura del quechua en el Perú desde comienzos del siglo XX: Escritura en quechua y sociedad serrana en transformación: Perú 1920-1960 (Durston, 2019). ${ }^{2}$ A lo largo de cinco capítulos, el autor aborda los contextos locales y nacionales de la escritura en quechua y lo ocurrido en tres escenarios principales: Cusco, Ayacucho y Huanta, con un capítulo final dedicado a los debates generados en torno a la ortografía quechua y la repercusión negativa que las disputas tuvieron en los distintos aspectos implicados en la literacidad del idioma.

A través de tres estudios de caso, Durston permite completar — O, mejor dicho, continuar - el conocimiento de una realidad que había sido abordada con especial acuciosidad por el profesor César Itier $(1995,2000)$, aunque referida principalmente a textos comprendidos en el periodo anterior (1895-1919), correspondiente al boom del teatro inca en el Cusco en los años posteriores a la guerra del Pacífico. La escritura en quechua sirvió entonces como una forma de expresar las ambiciones de liderazgo cultural y político de los intelectuales cusqueños frente al centralismo limeño (Itier, 1995, 2000). Durston abordará para la región del Cusco la relevante y controvertida figura de Andrés Alencastre Gutiérrez (1909-1984), que tiene su inicio también en los años veinte, pero pertenece a una generación posterior y cuya influencia alcanzará varias décadas hasta los años sesenta-setenta, en que el afán por retratar sociedades locales será remplazado por «orientaciones revolucionarias de proyección nacional» (Durston, 2019, p. 14).

2 Dos de esos capítulos se habían publicado con anterioridad (Durston, 2014a, 2014b). 
La región sudperuana contaba, además, con una larga tradición escrita, empleada principalmente por presbíteros para la oratoria sagrada (Durston, 2011), que permitió elaborar una suerte de quechua estándar colonial y en la que se desarrolló finalmente una valiosa tradición teatral con obras como Usca Paucar y Ollantay, y que incluye obras de teatro como las de Juan Espinosa Medrano, editadas por Taylor $(2002,2003)$ y por el propio Itier (2010). Fue en ese espacio letrado donde el profesor Durston comenzó sus indagaciones sobre los textos pastorales escritos en quechua, trabajos iniciales que contaron con la ayuda de Laura Gutiérrez y Melecio Tineo, del Archivo Arzobispal de Lima, y de los profesores Juan de Castromonte y Rodolfo Cerrón-Palomino (Durston, 2002, 2007, 2008).

En un breve panorama referido al siglo XIX, Gonzalo Espino (2003) se refería a la escritura vernácula como «aldea letrada quechua», desdeñada por tratarse de «literaturas no canónicas» que habrían sido silenciadas o excluidas por la intelectualidad nacional como prácticas discursivas de grupos subalternos», y que demostrarían que debajo de la aparente homogeneidad del espacio constituido por la escritura del siglo XIX aflorarían «espacios controversiales y contradictorios» (Espino Relucé, 2003, p. 77). Sin embargo, solamente alude escuetamente a las proclamas en quechua que realistas y patriotas difundieron en el proceso de independencia, al drama Ollantay y a la Miscelánea literaria en quechua y español (1850) de Carlos Felipe Beltrán. De todo ello resulta «uno de los procesos de fundación de las literaturas peruanas» (Espino Relucé, 2003, p. 82).

Alan Durston (2019, p. 14) destaca que el periodo por él estudiado «se caracteriza por proyectos escriturales de carácter regionalista que fueron también altamente innovadores». El resultado fue en realidad una eclosión de obras que en su momento gozaron de gran aprecio y popularidad. Las intenciones y los intereses que persiguen los cultores del quechua fueron variados y responden a tendencias ideológicas muy distintas. Sus textos conforman un conjunto que lograron premiaciones o reconocimientos y que incluso, en algunos 
casos, establecieron conexiones importantes con el mundo académico. Son décadas que beneficiaron a muchos intelectuales serranos (entre ellos José María Arguedas, Edmundo Delgado Vivanco, José María Benigno Farfán y Efraín Morote Best) con la expansión del sector educativo y la creación de cátedras universitarias, hasta constituir «la época dorada de los estudiosos y recopiladores del folclor quechua» (Durston, 2019, p. 37). Entre las circunstancias que promovieron esta explosión de estudios quechuas destaca el impulso de los movimientos indigenistas y regionalistas, que habían gozado de la simpatía del régimen de Augusto B. Leguía (1919-1930), pero también del interés de los intelectuales vinculados con José Carlos Mariátegui y la revista Amauta. ${ }^{3}$ También los inicios de la filología quechua en la Universidad de San Marcos (Durston, 2014c). En los años cuarenta nuevamente se emprendió el fomento del quechua y el aimara en el marco del Primer Congreso Indigenista Interamericano y los proyectos de alfabetización dirigidos por Luis E. Valcárcel, ministro de educación durante el gobierno de José Luis Bustamante (1945-1948). Sin embargo, en el transcurso de estos acontecimientos la lengua quechua pasó a ser una lengua minoritaria usada primordialmente en contextos rurales:

La historia del quechua durante la primera mitad del siglo XX encierra una gran paradoja: los mismos factores que causaban su retirada demográfica contribuían a su resurgimiento como lengua escrita. La centralización política provocó respuestas regionalistas, el crecimiento económico causó la expansión de sectores medios quechuahablantes y la ampliación del sistema educativo, vehículo del español que fomentó también la difusión de la literacidad en quechua. Incluso la migración a Lima ocasionó la eclosión de nuevas formas de escritura en quechua. ${ }^{4}$

3 Durston (2012) aborda el papel jugado por el cultivo de la lengua quechua y el desarrollo del indigenismo en el régimen de Augusto B. Leguía. Sobre los debates indigenistas en el Cusco, véase López Lenci (2007).

4 Durston (2019, p. 27). 
Un ejemplo significativo de esa eclosión será el caso del Grupo Huanta, que Durston estudia con especial profundidad, mientras apenas esboza unas líneas respecto de la escritura de otros migrantes como Salomón Velazco Yáñez, quien reunió en Lima una extensa colección de relatos y tradiciones de la zona de Coracora (Ayacucho), su pueblo natal. En Lima los migrantes de origen popular tenían más facilidad de acceder a la cultura escrita, aunque el proyecto «de recrear textualmente el lejano terruño» (Durston, 2019, p. 38), parece ser más fruto de la nostalgia que síntoma de vitalidad de la lengua.

Son tres los escenarios principales de la escritura en quechua. El cultivo del quechua huamanguino sirvió a Moisés Cavero para denunciar el latifundismo, pero también para desarrollar un proyecto de signo conservador que aspiraba al papel de guía y benefactor paternalista del campesinado. La forma literaria del quechua local serviría «para preparar a la juventud urbana para cumplir ese papel de liderazgo regional»(Durston, 2019, p. 39). De hecho, su obra más destacada, el drama Qisanpi sapan urpikuna (Palomas solitarias en su nido), se presentó en la Semana Santa del año 1920, en una velada organizada por el Círculo de Obreros Católicos de Ayacucho, que parece responder al anticlericalismo de la novela Aves sin nido (1889), de la escritora cusqueña Clorinda Matto de Turner. ${ }^{5}$ «Los protagonistas de Qisanpi —excelentes católicos — son víctimas del latifundismo, no de los malos curas» (Durston, 2019, p. 42).

Una de las características centrales del teatro quechua ayacuchano fue la misión educativa (Durston, 2014a), acorde con el indigenismo favorecido por el régimen del Oncenio: «glorifica al indio y denigra al terrateniente, pero sin invitar a la rebelión ni criticar a la Iglesia» (Durston, 2019, p. 43). Durston destaca especialmente la habilidad de Cavero Cazo para la versificación quechua y su afán de

5 Por error se afirma que Matto de Turner era una escritora «protestante» (Durston, 2019, p. 41). 
desarrollar un estilo pulido y purificado cercano al habla popular, pero más adecuado para su uso literario y escolar, que trataba de excluir castellanismos introducidos al quechua hablado e incluía algunos términos del quechua eclesiástico (Durston, 2019, p. 52). Pese a ello señala que su poesía ha sido excluida de las antologías, seguramente por su temática y por su posicionamiento político contrario a los agitadores mestizos (apristas y comunistas), que representaban para Cavero tendencias funestas.

Mayor atención recibe la obra de Andrés Alencastre, según Durston, «el escritor más famoso del quechua del siglo XX» (Durston, 2019, p. 55). Más allá de las contradicciones señaladas por diversos estudiosos respecto de este gamonal y poeta socialista cusqueño (quien produjo una honda impresión en Arguedas) y de la mitificación de su figura «emblema de las contradicciones del indigenismo» (Durston, 2019, p. 56), se describe con detalle la intensa actividad realizada por Alencastre en la escena costumbrista en Cusco como músico, actor y compositor de piezas musicales y obras de teatro. Su formación coincide con un periodo dorado para el proyecto quechuista que buscaba resucitar la cultura incaica a través de su lengua, reflejado en la fundación del Instituto Histórico del Cuzco (1913) por Luis E. Valcárcel, acompañado de figuras relevantes de la intelectualidad local como Mariano C. Rodríguez y José Gabriel Cosio, principal estudioso del teatro quechua colonial. La ciudad del Cusco había conocido también una profusión asombrosa de revistas literarias y culturales (López Lenci, 2007).

La tradición del teatro incaico enfocado en representar costumbres campesinas, junto con cantos y bailes, formaba parte de un programa folclórico alimentado por los debates intelectuales promovidos por Valcárcel y José Uriel García. César Itier (1995, 2000) había investigado una docena de obras de teatro en quechua de Julio Rouvirós, Inocencio Mamani y Nemesio Zúñiga, en las que con frecuencia se denunciaban los abusos de los representantes del Estado. La celebración del cuarto centenario de la fundación española del 
Cusco en 1934 incluyó la representación de varias obras de teatro en quechua, entre ellas El pongo Killkito, la primera obra conocida de Alencastre, quien formaba parte de un conjunto folclórico de Canas, su pueblo natal. Preparó otro drama para el centenario del Inca Garcilaso, El ch'allakuy (1939). Ambas obras serían publicadas en 1954, gracias a que Alencastre trabó contacto con el mundo académico al convertirse en profesor de quechua en la Universidad del Cusco en 1949 y vincularse con la revista Tradición de Efraín Morote Best y colaborar con el catedrático francés Georges Dumézil.

Las comedias de Alencastre reflejan la vida en una hacienda con temas de noviazgo e incomunicación. Los peones, luego de la herranza o ch'allakuy, intentan quemar la casa del hacendado instigados por el subprefecto, pero en el ch'allakuy del año siguiente se logra la reconciliación porque todos son mestizos de sangre y neoindios por espíritu. Durston se muestra cauteloso respecto de la presunción de que el teatro de Alencastre es realista tanto en los hechos retratados como en el lenguaje empleado. Ciertamente no es un quechua literario sino fiel al habla vernácula de la zona, pero la separación entre el uso del español y el quechua parece demasiado rígida para considerarse realista:

Refleja más bien una visión jerárquica de la sociedad serrana que enfatiza las diferencias entre indios y mistis, por muy neoindios que estos fueran. Los mistis son los únicos en dominar los dos idiomas pero los mantienen rigurosamente separados. ${ }^{6}$

A partir de los años cuarenta el teatro quechua prácticamente desapareció, conforme el país entraba en un periodo de democratización y crecimiento económico que hacían innecesario reflejar dramáticamente la denuncia de abusos o la crítica de los representantes del Estado. Alencastre se vincula a la Academia de la Lengua

6 Durston (2019, p. 64). 
Quechua y publica lecciones de quechua en la Revista Universitaria (1950). Finalmente, es autor del corpus de poesía lírica más extenso de la literatura quechua, aunque sea un corpus, siempre según Durston, muy desigual, pues cae frecuentemente en lo retórico. También escribe numerosas composiciones de circunstancias, recibiendo importantes premios literarios. Alencastre se convirtió así en el primer quechuista celebridad, una especie de poeta oficial de la ciudad, capaz de ser intérprete y creador a la vez del folclor, como inventor de tradiciones, puesto que en cierto grado creaba aquello que mostraba como cultura popular, mediatizado por el impulso arqueológico del incaísmo (Durston, 2019, pp. 76-78).

El Grupo Huanta es estudiado aquí por primera vez con datos de primera mano y testimonios de familiares. Teodoro Meneses Morales, uno de los principales estudiosos del teatro quechua colonial, ${ }^{7}$ formó este grupo junto con Mauro Salvador Pérez Carrasco y Porfirio Meneses Lazón, pariente cercano y cuñado suyo. ${ }^{8}$ Se trata de un grupo de migrantes andinos que se destacaron como pioneros en el campo de la narrativa quechua (Durston, 2019, p. 80). Huanta es una ciudad pequeña del departamento de Ayacucho, que protagonizó una serie de rebeliones en las que campesinos y hacendados hicieron frente común contra el Estado. Durston (2019, p. 81) reconoce la importancia de la horizontalidad de la sociedad huantina como un factor para que «los intelectuales huantinos asumieran el quechua como una lengua propia más que los ayacuchanos o los cusqueños», pero también reflexiona sobre «cómo el contexto migrante influyó en sus proyectos escriturales».

7 Meneses Morales fue contactado en 1936 por el director del Instituto de Filología de San Marcos, el italiano Ippolito Galante, para dictar cursos de quechua y publicar dramas coloniales en quechua. Ver Durston (2014c).

8 También se relacionaron estrechamente con otros quechuistas como Víctor Rondinel Ruiz, Artemio Huilca Galindo, Juan Salvador Cavero León y Sixto Clodoaldo Soto. 
Colaboraron en la revista Huanta (1948-1949) y luego en Pregón Huanta (1952), con cuentos y noticias en quechua y castellano. La sección quechua se inicia con un breve texto titulado Sara tusuchi (Hacer bailar el maíz), que describe un juego infantil. Entre los textos reseñados destaca Tinkuy (El encuentro), de Pérez Carrasco. Junto al interés por las obras clásicas de la época colonial, Meneses Morales expresaba su deseo de que el público bilingüe leyera una literatura moderna que estaba por hacerse. De hecho, Tinkuy se aleja de los patrones de la narrativa oral, al emplear un narrador omnisciente, recurso muy común en la prosa de ficción en otras lenguas, pero raro en quechua. ${ }^{9}$ El Grupo Huanta propone así en sus relatos formas nuevas de literatura en quechua, con el deseo de modernizarla y asimismo desarrollar «una comunidad de lectores» (Durston, 2019, p. 94). Quizá influyó el hecho de ser profesionales de clase media en el contexto migrante limeño: «Además, el fuerte asociacionismo que se daba en Lima entre migrantes de la misma localidad fomentaba el desarrollo de proyectos grupales, una de las claves de la innovación escritural» (Durston, 2019, p. 95).

Finalmente, Durston destaca como objetivo común de todos los autores estudiados el deseo de alcanzar «la armonía al interior de las sociedades serranas» (Durston, 2019, p. 115); asimismo, señala que el boom quechuista tomó formas distintas según la localidad, y es necesario discutir por qué Cusco no fue el epicentro de la innovación en la escritura del quechua (Durston, 2019, p. 116). Los autores desarrollaron una estrategia peculiar para publicar sus obras, lo que pone en evidencia «las limitaciones que pesaban sobre el desarrollo del quechua como lengua escrita». Su conclusión respecto al declive de la escritura en quechua alrededor de 1960 es también clara: «los proyectos regionalistas perdieron fuerza en una época de movimientos campesinos y discursos revolucionarios de proyec-

9 Son especialmente interesantes los comentarios respecto del novedoso empleo que hacen estos escritores de los evidenciales quechuas (Durston, 2019, p. 90). 
ción nacional». Además, está claro que en el contexto de «una sierra convulsionada por rápidas transformaciones y profundos conflictos sociales», ya no había un escenario regional que diera asidero temático y público a los textos: «El regionalismo como proyecto cultural había dado cabida a una excepcional diversidad y complejidad en la escritura en quechua y su declive creó un vacío difícil de llenar» (Durston, 2019, p. 118).

Alan Durston describe, explica y valora en un panorama amplio, atractivo y variopinto, una realidad letrada poco o apenas conocida, y además lo hace con una hondura y una perspicacia singular. Su estudio incluye no solamente la mención o el análisis de los textos, sino la revisión de archivos, el expurgo de periódicos y revistas y el testimonio directo de familiares de los autores estudiados, con un método a la vez crítico y biográfico, en la línea de la historia social de las lenguas. Deja como tarea pendiente el estudio de la producción velasquista en quechua y del movimiento literario en quechua protagonizado, entre otros, por el huancavelicano Pablo Landeo Muñoz, propulsor de la revista literaria Atuqpa Chupan (2012-), íntegramente escrita en quechua. Cabe preguntarse por qué no incluyó en su libro su interesante estudio sobre la escritura en quechua en la región puneña. Inocencio Mamani y la poesía vanguardista en quechua (Durston, 2014b) hubiera podido ser un capítulo más del libro. Según el propio Durston (2019, p. 15), el altiplano era un importante centro de la innovación escritural en quechua y requeriría un análisis especial. Tal vez pueda ofrecerlo en una segunda edición del libro.

Es más que posible que el conocimiento aportado en este libro pueda ofrecer una mejor base a los estudios dedicados a los factores sociales y lingüísticos que influyen en el uso que los migrantes hacen del español y el quechua en distintas ciudades del país. Amy Firestone (2017) atiende con un método que combina la sociolingüística y la antropología el habla de los jóvenes en Ayacucho y Arequipa. Itier (2000, p. 89) hacía hincapié en que el carisma de 
la lengua de los incas era una espada de doble filo: el ímpetu de cultivar un quechua presuntamente arcaico y puro habría mermado su posición como lengua de comunicación polivalente. En este sentido habría que poner en relación esta tradición escrita con el afán de guardar por escrito muchos textos quechuas de tradición oral, como los cuentos quechuas registrados por Max Uhle o por Adolfo Vienrich, y ya a mediados del siglo XX por Jorge Lira y José María Arguedas. ${ }^{10}$ También se podría completar el panorama con los textos vinculados a representaciones teatrales festivas como las relacionadas con el tema de la degollación del inca (Badillo, 2015).

Como comentario final, cabe señalar el interés que presenta el análisis de los textos vinculado a distintos aspectos implicados en la literacidad del idioma (educación, normalización, prensa, publicaciones), atendiendo también a circunstancias de la historia social del idioma (rebeliones, construcción de carreteras, difusión de ideas y movimientos políticos, creación de instituciones culturales o religiosas, etc.). A estos aspectos habría que añadir, tal vez, el impulso del turismo incipiente y el interés de reflejar la imagen que sobre el mundo andino buscaban proyectar los viajeros sobre sus relatos de viajes, así como la elaboración de festividades que buscaban revivir tradiciones incaicas, como las celebraciones del Inti Raymi, que se dotaron de textos dramáticos basados, al menos en parte, en la tradición aquí estudiada.

\section{REFERENCIAS}

BAdillo, J. (2015). Apu Inka-A soberano Inca Atawallpaman-Atawallpa. Una y mil muertes del Incarri en representaciones populares. Lima: edición del autor.

Durston, Alan (2002). «El Aptaycachana de Juan de Castromonte». Boletín del Instituto Francés de Estudios Andinos, vol. 31, núm. 2, pp. 219-292.

10 Ver los estudios reunidos en Uhle (2003). 
Durston, Alan (2007). Pastoral Quechua: The History of Christian Translation in Colonial Peru, 1550-1650. Notre Dame, IN: University of Notre Dame Press.

Durston, Alan (2008). «Native-Language Literacy in Colonial Peru: The Question of Mundane Quechua Writing Revisited». Hispanic American Historical Review, vol. 88, núm.1, pp. 41-70.

Durston, Alan (2011). «Quechua Political Literature in Early Republican Peru (1821-1876)». En: Paul Heggarty y Adrian Pearce (eds.), History and Language in the Andes. Nueva York: Palgrave Macmillan, pp. 165-186.

Durston, Alan (2012). «Quechua for the Patria Nueva: Indigenous-Language Government Propaganda in 1920s Peru». En: 126th Annual Meeting of the American Historical Association. Ponencia presentada en Chicago, 5-8 de enero.

Durston, Alan (2014a). «El teatro quechua en la ciudad de Ayacucho, Perú, 1920-1950». Corpus: Archivos Virtuales de la Alteridad Americana, vol. 4, núm. 2. Disponible_en: <http://corpusarchivos.revues. org/1280>. Consulta: 20.11.2019.

Durston, Alan (2014b). «Inocencio Mamani y el proyecto de una literatura indígena en quechua (Puno, Perú, década de 1920)». A Contracorriente. Una revista de historia social y literatura en América Latina, vol. 11, núm. 3, pp. 218-247. Disponible en: <https://acontracorriente.chass.ncsu.edu/index.php/acontracorriente/article/ view/826>. Consulta: 20.11.2019.

Durston, Alan (2014c). «Ippolito Galante y la filología quechua en los años 1930 y 1940». Lexis, vol. 38, núm. 2, pp. 307-336.

Durston, Alan (2015). «Indigenous Languages and the Historiography on Latin America». Storia della Storiografía, vol. 67, núm. 1, pp. 51-65.

Durston, Alan (2020). «Las lenguas indígenas y la historiografía de América Latina». Allpanchis, vol. 45, núms. 81/82, pp. 437-468. 
Espino ReLuCÉ, Gonzalo (2003). «Las literaturas peruanas del siglo XIX y la aldea letrada quechua». Ajos y zafiros. Revista de literatura, núm. 5, pp. 77-85.

Firestone, A. (2017). «Combinamos el quechua». Lengua e identidad de los jóvenes urbanos en el Perú. Lima. Instituto de Estudios Peruanos.

Itier, César (1995). El teatro quechua en el Cuzco. Tomo I. Dramas y comedias de Nemesio Zuñiga Cazorla: Qurichuspi (1915), T'ikabina (1934), Katacha (1930?). Lima: Instituto Francés de Estudios Andinos; Centro de Estudios Regionales Andinos «Bartolomé de las Casas».

Itier, César (2000). El teatro quechua en el Cuzco. Tomo II. Indigenismo, lengua y literatura en el Perú moderno. Lima: Instituto Francés de Estudios Andinos; Centro de Estudios Regionales Andinos «Bartolomé de las Casas».

López Lenci, Y. (2007). El Cusco, paqarina moderna. Cartografía de una modernidad e identidad en los Andes peruanos (1900-1935). Lima: Instituto Nacional de Cultura; Dirección Regional de Cultura de Cusco.

TAYLOR, G. (2002). Sermones y ejemplos. Antología bilingüe castellano-quechua. Siglo XVII. Lima: Instituto Francés de Estudios Andinos; Lluvia Editores.

TAYLOR, G. (2003). El sol, la luna y las estrellas no son Dios... La evangelización en quechua. Siglo XVI. Lima: Instituto Francés de Estudios Andinos; Pontificia Universidad Católica del Perú.

UhLE, Max (comp.) (2003). El cóndor y el zorro. Edición y prólogo de W. Kapsoli. Lima: Universidad Ricardo Palma; Embajada de la República Federal de Alemania.

Fecha de recepción: 2 de diciembre de 2020. Fecha de aceptación: 20 de diciembre de 2020. Fecha de publicación: 30 de junio de 2021. 